\title{
Review Article \\ Oxidative Damage and Antioxidative Therapy in Systemic Sclerosis
}

\author{
Bogna Grygiel-Górniak and Mariusz Puszczewicz \\ Department of Rheumatology and Internal Medicine, Poznan University of Medical Sciences, 28 Czerwca Street 135/147, \\ 61-545, Poznan, Poland \\ Correspondence should be addressed to Bogna Grygiel-Górniak; bgrygiel@ump.edu.pl
}

Received 19 May 2014; Revised 14 August 2014; Accepted 14 August 2014; Published 8 September 2014

Academic Editor: Yung-Hsiang Chen

Copyright (C) 2014 B. Grygiel-Górniak and M. Puszczewicz. This is an open access article distributed under the Creative Commons Attribution License, which permits unrestricted use, distribution, and reproduction in any medium, provided the original work is properly cited.

\begin{abstract}
Systemic sclerosis (SSc) is an autoimmune connective tissue disorder of unknown etiology. This disease is characterized by a large variety of clinical patterns, which include the fibrosis of skin and visceral organs causing a variety of clinical manifestations. Genetic and environmental factors participate in the etiology of this disease; however, recently many studies underline the oxidative background influencing the course and complications of this disease. Reactive oxygen species (ROS) synthesized in SSc can mediate extra- and intracellular oxidative processes affecting endothelial cells and fibroblasts. The estimation of prooxidative markers in the pathogenesis of SSc can enable the identification of useful markers for disease activity and, thus, may help in planning appropriate therapy focusing on the fibrotic or vascular pattern. Recently, many attempts have been made to find antioxidative molecules (nutritional and pharmacological) reducing the prooxidant state in a variety of cells-mainly in endothelium and proliferating fibroblasts. This paper presents both the background of oxidative stress processes in systemic sclerosis mediated by different mechanisms and the evidence suggesting which of the dietary and pharmacological antioxidants can be used as therapeutic targets for this disease.
\end{abstract}

\section{Introduction}

Systemic sclerosis is an autoimmune disease characterized by vascular hyperreactivity and fibrosis of skin and visceral organs $[1,2]$. The degree of skin fibrosis, immunological profile, and microvascular dysfunction determines the clinical classification of the disease, which includes limited (ISSc) and diffuse (dSSc) cutaneous SSc [3, 4]. An excessive fibrosis is the most characteristic pathological manifestation of SSc, particularly evident in the diffuse cutaneous form of this disease [3]. The overproduction of the extracellular matrix by fibroblasts and myofibroblasts is responsible for increased collagen synthesis and its deposition in the skin, lungs, heart, gastrointestinal tract, kidney, tendons, and ligaments $[2,3]$. Increased fibrosis causes organ dysfunction and is responsible, to a large extent, for morbidity and mortality in SSc.
In the development of SSc, many genetic and environmental factors may initiate the onset and stimulate the progression of the disease [5]. However, recently many studies underline the possible role of oxidative stress processes in the pathogenesis of SSc and show a new aspect of this disease (Figure 1) [6-9]. The production of reactive oxygen species (ROS) by skin and visceral fibroblasts as well as endothelial cells has been suggested as a background pathology, mainly in progressive SSc [6]. Synthesized ROS include superoxide anions $\left(\mathrm{O}_{2}{ }^{--}\right)$, hydrogen peroxide $\left(\mathrm{H}_{2} \mathrm{O}_{2}\right)$, hydroxyl radicals $\left({ }^{\circ} \mathrm{OH}\right)$, and/or peroxynitrite $\left(\mathrm{ONOO}^{-}\right)$(Figure 2$)$. Indeed, skin and visceral fibroblasts spontaneously produce large amounts of ROS that trigger collagen synthesis $[6,7]$. Given the fact that oxidative stress is involved in the pathogenesis of this disease, many trials with antioxidative treatment have been undertaken to prevent proliferation of the fibroblasts and inhibit the progression of SSc [9-20]. 


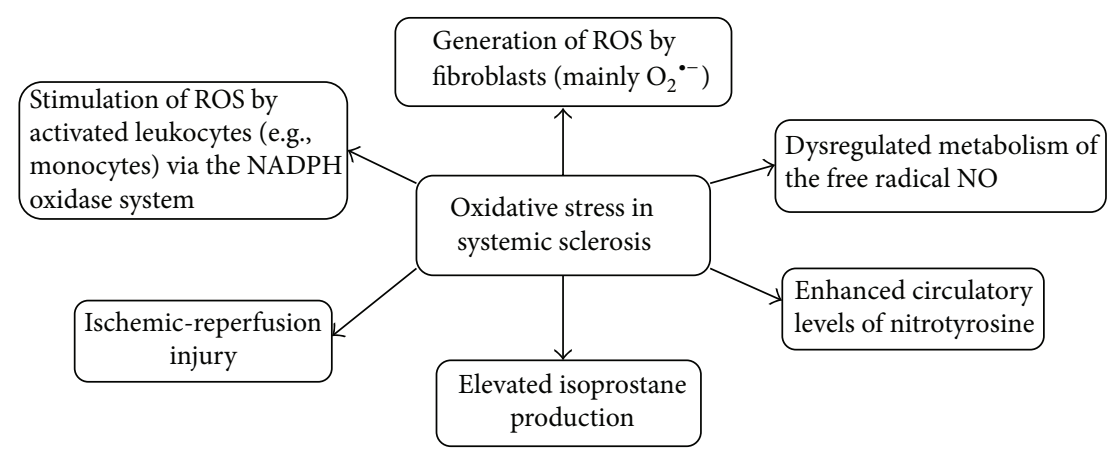

FIGURE 1: The main mechanisms of oxidative stress in systemic sclerosis. NADPH oxidase: nicotinamide adenine dinucleotide phosphateoxidase; oxLDL: oxidized low-density lipoprotein; ROS: reactive oxygen species; $\mathrm{O}_{2}{ }^{--}$: superoxide anions.

In this paper, we summarize the role of oxidative stress processes in the development of various patterns of SSc and describe the mechanisms of action of different prooxidant molecules synthesized by endothelial cells and fibroblasts. We also discuss the efficiency of the physiological antioxidant system in the development and progression of the disease, the possibilities of the beneficial influence of pharmacological and nutritional antioxidants, and putative therapeutic strategies, which could be effective in the supportive treatment of systemic sclerosis.

\section{The Basic Background Pathology of Oxidative Stress in Systemic Sclerosis}

Oxidative stress processes are one of the main background mechanisms present in many metabolic, cardiovascular, neurodegenerative, and neoplastic diseases and many others [6, $13,18,20-23]$. Because of the common prevalence of prooxidant activity in the development of various pathologies, scientific curiosity has also focused on systemic sclerosis. Also in the early stages of systemic sclerosis, oxidative stress is considered to be a background factor in the development and activity of this disease $[6,8-11,20,24]$, and it is suggested as contributing to clinical manifestations associated with SSc [6]. In in vitro studies, sera from patients with SSc can induce the production of ROS in endothelial cells and in proliferating fibroblasts [9]. Studies on animal models have suggested that oxidative processes can influence the onset and course of this disease [24-27]. The injection of intradermal ROSgenerating substances stimulates the development of skin changes typical for local and systemic SSc [24].

Prooxidants may also increase the production of autoantibodies. In animal models and clinical studies, local production of hypochlorous acid $(\mathrm{HOCl})$ or hydroxyl radicals can stimulate the immune response and the production of antiDNA topoisomerase 1 autoantibodies, whereas the generation of peroxynitrite triggers the production of anticentromeric protein B antibodies [24, 28]. Some studies have even shown that the presence of autoantibodies in endothelial cells and in fibroblasts in SSc is not correlated with serum-induced ROS production or cell proliferation [29, 30]. However, the role of autoantibodies cannot be totally ruled out. The above-mentioned phenomenon is also confirmed by antiPDGRF antibodies (anti-PDGFR Abs), which can trigger the production of ROS and, thus, activate SSc development [31].

2.1. Oxidative Stress in Fibroblastic Cells. Unquestionably, permanent overproduction of ROS stimulates the inflammatory reaction, activates the differentiation of fibroblasts into myofibroblasts [32], stimulates the growth of dermal and visceral fibroblasts [7], causes fibrotic complications [33, 34 , and (in high concentrations) can induce cell apoptosis (Figure 2) [35-37].

Fibrosis can be activated by $\mathrm{NO}$ and is associated with digital ischemia or pulmonary arterial hypertension $(\mathrm{PAH})$ $[5,38]$. The extremely disturbed metabolism and overproduction of $\mathrm{NO}$ cause increased synthesis of superoxide anions, $\mathrm{O}_{2}{ }^{--}$, and peroxynitrite, $\mathrm{ONOO}^{-}$, which lead to cell injuries and death $[6,37,39,40]$. NO is largely oxidized to nitrate $\left(\mathrm{NO}_{3}{ }^{-}\right)$and nitrite $\left(\mathrm{NO}_{2}{ }^{-}\right)$and increased plasma ratio $\mathrm{NO}_{3}{ }^{-} / \mathrm{NO}_{2}{ }^{-}$levels are found $[38,39]$. Additionally, an elevated nitration of plasma proteins (measured by $\mathrm{ONOO}^{-}$ markers) is found in many organs, including skin fibroblasts [41]. Moreover, in fibrogenesis NO directly stimulates transcription factors (such as NF- $\kappa \mathrm{B}, \mathrm{SP}-1$, and AP which inhibit collagen gene expression) [42] and regulates prolyl hydroxylase-an enzyme important in the posttranslational processing of collagen [43].

$\mathrm{NO}$ is synthesized from L-arginine by NO synthase (NOS). NOS is expressed in three main isoforms: neuronal (nNOS or NOS1), endothelial (eNOS or NOS3), and inducible (iNOS or NOS2). The last one is present mainly in the inflammatory state of fibroblasts $[44,45]$. In sites of active inflammation, the stimulated iNOS isoform is responsible for increased synthesis of $\mathrm{NO}$, which is associated with raised $\mathrm{O}_{2}{ }^{--}$production by macrophages or activated fibroblasts [46]. With the progression of the disease, the production of iNOS is upregulated in skin fibroblasts [45]. Another synthase-eNOS-also participates in the pathology of SSc and in eNOS knock-out mice decreased bioactivity of NO causes prolonged pulmonary fibrosis [47].

In SSc dermal fibroblasts, collagen synthesis is also promoted by platelet-derived growth factor (PDGF) and its receptor (PDGFR) promotes fibrosis. PDGFR is phosphorylated upon PDGF stimulation and is dephosphorylated 


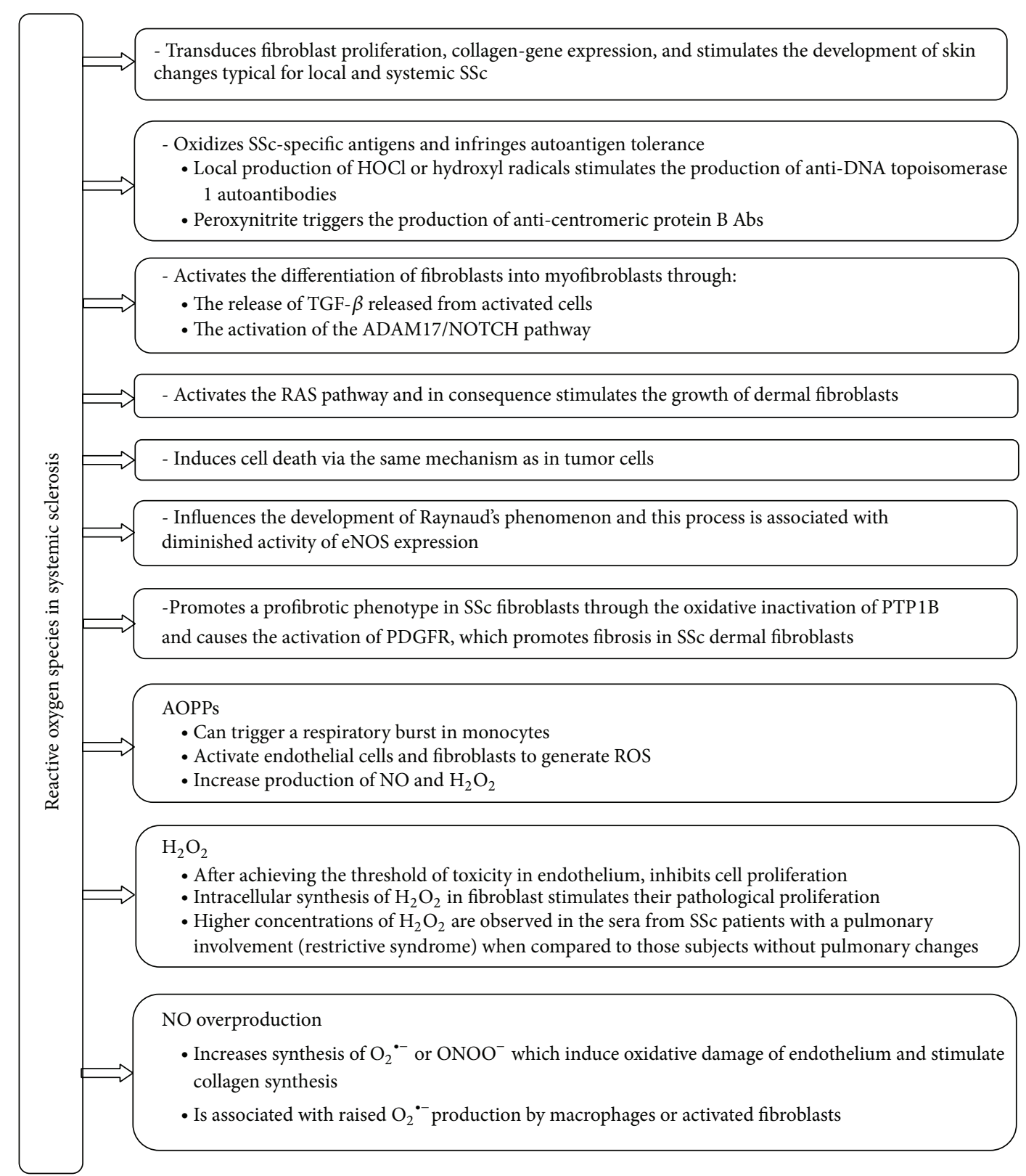

FIGURE 2: The role of oxidative stress in systemic sclerosis. HOCl: hypochlorous acid; TGF- $\beta$ : transforming growth factor $\beta$; ADAM17/NOTCH: ADAM17 (disintegrin and metalloproteinase domain-containing protein 17; also known as TACE) involved in the activation of the Notch signaling pathway; Ras proteins: a family of related proteins involved in transmitting signals within cells through the Ras pathway and belonging to a class of proteins called small GTPase; eNOS: endothelial nitric oxide synthase (eNOS or NOS3); PTP1B: protein tyrosine phosphatases 1B; PDGFR: platelet-derived growth factor receptor; AOPPs: advance oxidation protein products; NO: nitric oxide; $\mathrm{H}_{2} \mathrm{O}_{2}$ : hydrogen peroxide; $\mathrm{O}_{2}{ }^{--}$: superoxide anions; $\mathrm{ONOO}^{-}$: peroxynitrite.

by protein tyrosine phosphatases (PTPs), including PTP1B. A study by Tsou et al. proved that ROS may promote a profibrotic phenotype in SSc fibroblasts through the oxidative inactivation of PTP1B, leading to pronounced activation of PDGFR [20]. In fibroblasts isolated from the skin of patients with diffuse SSc, levels of ROS and type I collagen were significantly higher and the amounts of free thiol were significantly lower when compared to normal fibroblasts. The activity of
PTP1B was inactivated by the raised levels of ROS in SSc fibroblasts [20]. Moreover, anti-PDGF receptor antibodies [31] and probably also environmental factors [31, 48, 49] could initiate a secondary self-maintained process that is associated with the production of advanced oxidation protein products (AOPPs). The elevated AOPPs concentration can trigger a respiratory burst in monocytes [50, 51]. AOPPs also activate endothelial cells and, to a lesser extent, fibroblasts to 


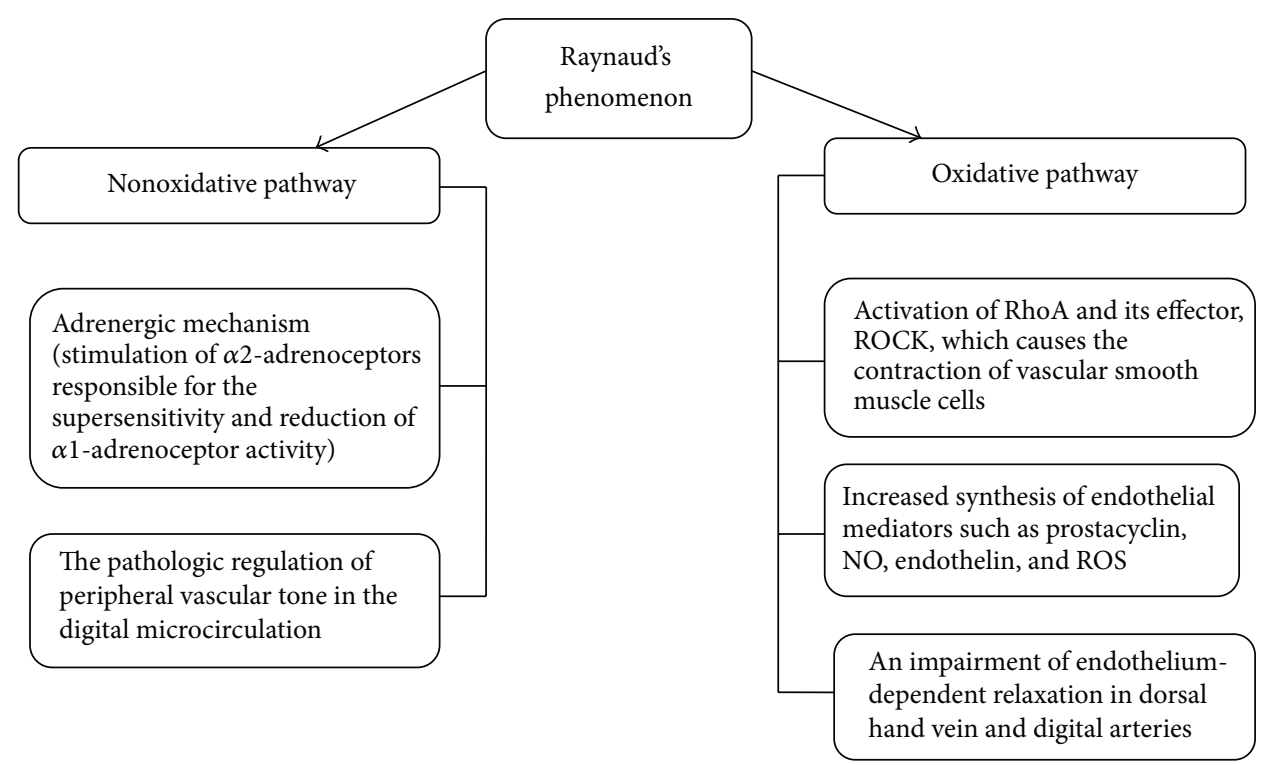

FIGURE 3: Background pathology of SSc-associated Raynaud's phenomenon. RhoA: Ras homolog gene family, member A (a small GTPase protein regulating the actin cytoskeleton in the formation of stress fibers); ROCK: Rho kinase; NO: nitric oxide, ROS: reactive oxygen species.

generate ROS. They can lead to the production of either NO or $\mathrm{H}_{2} \mathrm{O}_{2}$ in SSc fibroblasts and stimulate their proliferation $[6,7,9]$.

Another prooxidative molecule in SSc is 8-isoprostanea nonenzymatic eicosanoid produced during the random oxidation of tissue phospholipids by oxygen radicals [8, 52]. This is considered a reliable biomarker of oxidative stress and antioxidant deficiency because of its biochemical stability [52]. 8-Isoprostane level increases by 75 -fold in SSc patients in both forms, that is, dSSc and ISSc [8]. The serum concentration of this marker correlates inversely with pulmonary function and can be a useful serological marker for the severity of lung fibrosis in SSs $[8,53]$.

2.2. Oxidative Stress in Endothelial Cells. In SSc, oxidative processes cause the activation of and damage to endothelium. The mechanism of endothelial dysfunction is equivocal; however, the development of the vasculopathy includes many serological biomarkers (endothelin, which leads to vessel vasoconstriction), cell adhesion molecules (e.g., E-selectin), antiendothelial antibodies, and ROS (including nitric oxide) [39, 43]. Synthesized ROS selectively activate endothelial cells, leading to vascular complications [33, 34]. In SSc patients, endothelial cells reveal the ability to induce the production of $\mathrm{H}_{2} \mathrm{O}_{2}$. It is suspected that the high level of $\mathrm{H}_{2} \mathrm{O}_{2}$ generated in endothelium probably achieves the threshold of toxicity and thus inhibits intracellular processes [9]. When vascular disorders have been present, inhibited endothelial cell growth associated with increased nitric oxide (NO) overproduction has been observed [9, 38]. However, in SSc a paradoxical decrease in NO production by eNOS in endothelial cells is also observed, and this can be explained by the rapid reaction of $\mathrm{NO}$ and $\mathrm{O}_{2}{ }^{--}$to generate the reactive intermediate $\mathrm{ONOO}^{-}[6,39,41]$. Diminished
eNOS expression and vasculopathy contribute to Raynaud's phenomenon-a pathology often present in SSc patients [54, $55]$. With the progression of the disease, the production of eNOS is downregulated [45].

Another marker that directly reflects free radical formation in endothelium is 8-isoprostane-a potent vasoconstrictor revealing platelet proaggregant functions and stimulating endothelial cells to bind monocytes [56]. An increased level of isoprostanes correlates with the extent of vascular damage in Raynaud's phenomenon-a primary or secondary condition to SSc [52]. This vasculopathy occurs in more than $90 \%$ of patients with systemic sclerosis and results from an excessive, vasoconstrictive response to low temperatures and other stimuli. Many causes have been suggested in the pathogenesis of this vasculopathy (Figure 3). Cutaneous vasoconstriction by direct local cooling induces a response, which is in part adrenergically dependent (nonoxidative pathway). Local cooling causes a temperature-dependent inhibition of basal NOS activity (particularly nNOS and iNOS) $[57,58]$ associated with hypertrophy and occlusion of the vasculature [59].

Because the presynaptic blockade of noradrenalin release from vasoconstrictor nerve fibers does not completely eliminate the vessel spasm stimulated by low temperatures and the construction of a vascular bed is also observed in the internal organs, it is suggested that other nonadrenergic mechanisms could be involved in this process (oxidative pathway) $[60,61]$. The endothelial cells release mediators, such as prostacyclin, NO, and endothelin; increased ROS generation is observed as well $[46,62]$. NO acts as a physiological vasodilator and improves peripheral ischemia in SSc, but in Raynaud's phenomenon increased generation of NO during reperfusion injury reacts with superoxides and forms highly reactive hydroxyl radicals, which rapidly diffuse across cell membranes and lead to cell injury $[22,46]$. 


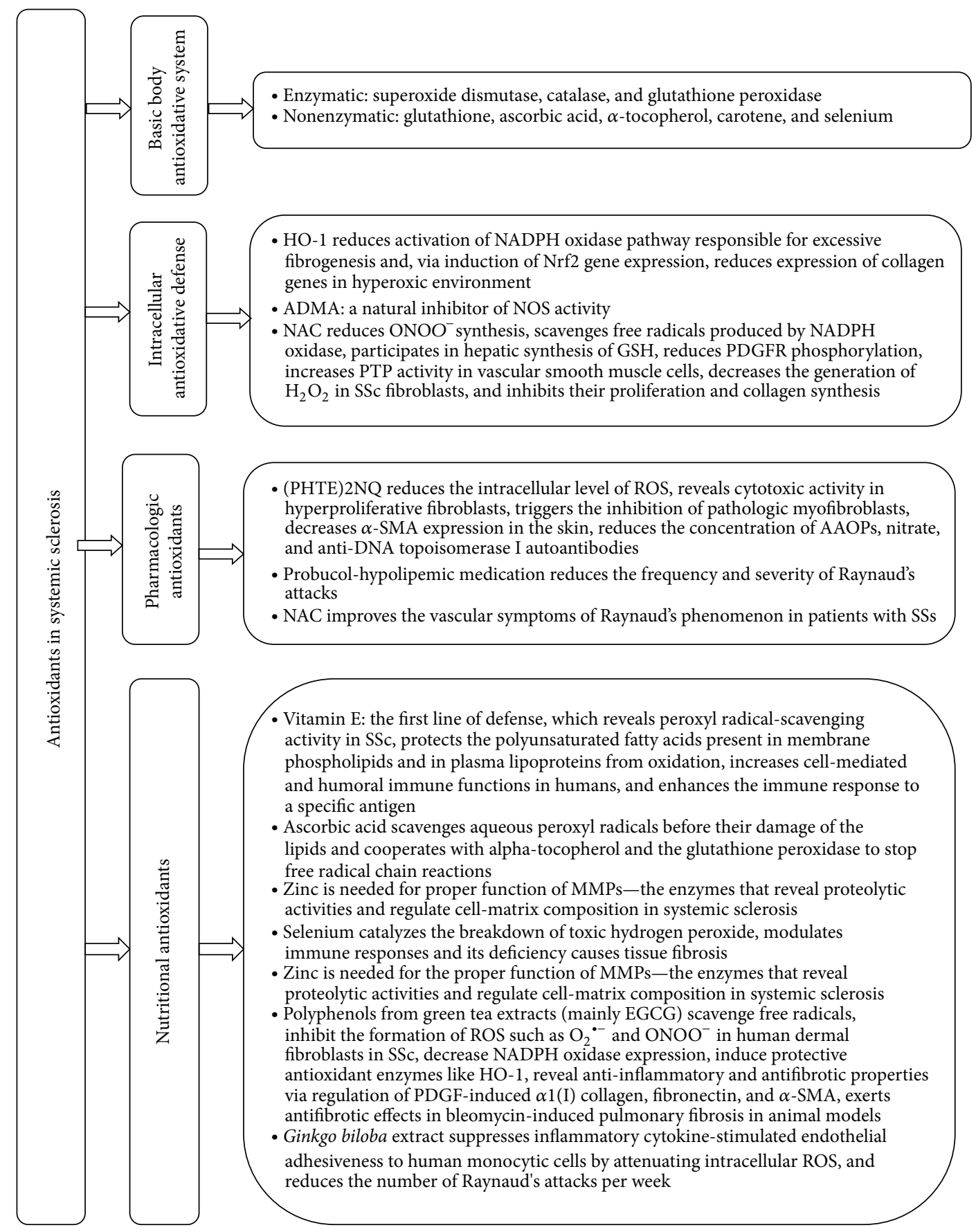

FIgURE 4: Antioxidative defense in systemic sclerosis. HO-1: haemoxygenase-1, NADPH oxidase: nicotinamide adenine dinucleotide phosphate-oxidase, Nrf2: nuclear factor erythroid-2-related factor 2, ADMA: asymmetric dimethylarginine, NOS: nitric oxide synthase, NAC: $\mathrm{N}$-acetyl-l-cysteine, $\mathrm{ONOO}^{-}$: peroxynitrite, GSH: glutathione, PDGFR: antiplatelet derived growth factor receptor, PTP: protein tyrosine phosphatases, $\mathrm{H}_{2} \mathrm{O}_{2}$ : hydrogen peroxide, (PHTE)2NQ: 2,3-bis(phenyltellanyl)-naphthoquinone, ROS: reactive oxygen species, $\alpha$-SMA: alpha-smooth muscle actin, AOPPs: advance oxidation protein products, MMPs: matrix metalloproteinase-1, EGCG: (-)-epigallocatechin3-gallate, $\mathrm{O}_{2}{ }^{--}$: superoxide anions, and PDGF: antiplatelet derived growth factor.

\section{Antioxidants in Systemic Sclerosis}

3.1. Antioxidant Defense Mechanism in SSc. Antioxidative defense involves not only enzymatic antioxidants (superoxide dismutase, catalase, and glutathione peroxidase) but also nonenzymatic molecules (glutathione, ascorbic acid, $\alpha$-tocopherol, carotene, and selenium). These contribute to the primary defense against ROS (Figure 4). Moreover, many antioxidative mechanisms are involved in attenuating intracellular oxidative stress. One of these is nuclear factor 
erythroid-2-related factor 2 (Nrf2) -the master regulator of inducible antioxidant responses, which can attenuate cellular injury from oxidative stress. Nrf2 is a mediator of the antioxidant response element (ARE) in regulatory regions of several antioxidant enzymes (such as glutathione peroxidase or superoxide dismutase and catalase) [63]. The lack of Nrf2 in animal models (Nrf2-/- knock-out mice) stimulates the expression of extracellular matrix genes such as collagens under a hyperoxic environment [63] and causes increased bleomycin-induced pulmonary fibrosis [64]. Nrf2 has a critical role in protection against pulmonary fibrosis through an enhancement of cellular antioxidant capacity and by the influence on lung Th1/Th2 balance (increased expression of Th2 cytokines, such as interleukin- 4 and interleukin-13 in the lungs of Nrf2-deficient mice is observed) [63, 64]. Thus, Nrf2 should be considered a potential factor for antifibrotic therapy in SSc.

Nrf2 influences haemoxygenase-1 (HO-1) activity. HO1 is the protective antioxidant enzyme induced by NO and $\mathrm{Nrf} 2 / \mathrm{HO}-1$ axis is a major mechanism in antioxidative defense and inflammation [23]. On the other hand, HO-1 is also responsible for physiological oxidative homeostasis inside cells via induction of $\mathrm{Nrf2}$ gene expression (HO-1/Nrf2 axis) [65]. HO-1 can diminish activation of the NADPH oxidase pathway responsible for an increase in collagen synthesis and myofibroblast differentiation in fibrosis [66]. Moreover, cells overexpressing HO-1 are more resistant to oxidant-induced toxicity than controls [21].

Another possible mechanism responsible for reduced production of NO is circulating ADMA- a natural inhibitor of NOS activity [67]. ADMA in the regulatory feedback mechanism causes decreased $\mathrm{NO}$ overproduction and the increased activity of this enzyme is present in late stages of SSc (mainly in diffuse SSc) [16, 43].

The molecule, which prevents oxidative damage in SSc, is $\mathrm{N}$-acetyl-l-cysteine (NAC). NAC acts as a precursor for the substrate (l-cysteine) in the synthesis of hepatic glutathione (GSH) and replenishes GSH in deficient cells [68-70]. NAC scavenges free radicals produced by the multicomponent nicotinamide adenine dinucleotide phosphate (NADPH) oxidase (Nox) [68], influences protein thiols, supports glutathione synthesis, and generates free sulfhydryl groups [69]. Moreover, NAC not only decreases cellular $\mathrm{O}_{2}{ }^{\cdot-}$ but also restores PTP1B activity along with an improvement of the PDGFR phosphorylation. In consequence, the numbers of tyrosine-phosphorylated proteins are diminished, the level of type I collagen is reduced, and the fibroblast proliferation is decreased $[20,68,70,71]$.

In fibrotic skin disorders, PDGF induces enzymes from Nox complexes, Nox1 and Nox2, while TGF $\beta$ stimulates Nox 4 to mediate fibrotic effects $[72,73]$. Nox enzymes are the major producers of endogenous ROS by fibroblast and activated leukocytes in the pathogenesis of skin fibrosis $[43,72,73]$. Nox enzymes not only promote fibroblast proliferation and collagen gene expression but also upregulate TGF $\beta 1, \alpha$-smooth muscle actin ( $\alpha$-SMA, the myofibroblast marker), chemokine ligand-2 (CCL-2, a chemoattractant for monocytes and T lymphocytes), and PDGFR [20, 43, 74-76]. Current understanding of Nox in SSc shows the potential possibilities of Nox-based antifibrotic therapy-a clinical target in the management of skin fibrosis (mainly in dSSc).

3.2. Antioxidants as Therapeutic Factors in the Supportive Treatment of SSc. Given the growing evidence of the influence of oxidative stress on the development and progress of systemic sclerosis, antioxidant therapy has been proposed as a supportive therapy in the pharmacological treatment of this disease $[10,11]$. The main aim of such therapy is to diminish ROS-induced endothelial damage and vasculopathy. However, there is limited evidence of the positive antioxidative effect of fibrotic processes in systemic sclerosis $[13,16,26$, $27,68]$. Classical antioxidants such as antioxidative vitamins (ascorbic acid, $\alpha$-tocopherol, and $\beta$-carotene) and minerals (zinc, selenium) have been found in lower concentrations in plasma of patients when compared to healthy controls $[10,11,77,78]$.

3.2.1. Antioxidative Vitamins. Vitamin E, a potent chainbreaking intracellular antioxidant and the first line of defense against lipid peroxidation, has been studied in SSc [12, 78]. Because of its peroxyl radical-scavenging activity, vitamin E protects the polyunsaturated fatty acids present in membrane phospholipids and in plasma lipoproteins. $\alpha$ Tocopherol mainly inhibits the synthesis of newly synthesized ROS, while $\gamma$-tocopherol traps and neutralizes existing free radicals $[12,79]$. Besides its positive influence in attenuating oxidative stress processes, vitamin E stimulates the body's defense, enhances humoral and cell immune responses, and increases phagocytic functions [80, 81]. The supplementation of this vitamin considerably increases cell-mediated and humoral immune functions in humans $[81,82]$.

Because Raynaud's phenomenon is related to ROSinduced endothelial damage, antioxidative therapy has also been suggested in this pathology [13]. However, some clinical trials have shown limited success in treatment with antioxidants such as $\alpha$-tocopherol or ascorbic acids (these vitamins did not improve microvascular perfusion after cold exposure and did not decrease urinary markers of oxidative stress such as $\mathrm{F}(2)$-isoprostanes) [83, 84].

More promising are the results of the use of vitamin E in pulmonary complications. Ostojic and Damjanov assessed the effects of $\alpha$-tocopherol $400 \mathrm{IU} /$ day $(268 \mathrm{mg} /$ day) and ascorbic acid 1,000 mg/day (given through 6 months) on skin thickening and lung function in patients with early diffuse cutaneous SSc. Patients treated with cyclophosphamide associated with antioxidant supplementation have a significantly lower skin thickening progression rate (STPR) when compared to patients only on cyclophosphamide monotherapy [13]. $\alpha$-Tocopherol upregulates the expression of cytosolic phospholipase-A2 and cyclooxygenase-1 and, in consequence, increases the release of prostacyclin, a potent vasodilator and inhibitor of platelet aggregation [85].

The dietary intake of ascorbic acid is also low in SSc patients and this is usually caused by the malabsorption syndrome resulting from increased collagen deposition in 
the intestines or bacterial overgrowth in SSc patients [86]. Another possible explanation is an altered renal clearance of the aqueous phase of ascorbic acid and its increased excretion in SSc subjects [87].

3.2.2. Antioxidative Minerals. Selenium is an essential part of enzyme glutathione peroxidase (GSH-Px), which catalyzes the breakdown of toxic hydrogen peroxide. Selenium deficiency causes tissue fibrosis [88]. Additionally, selenium reveals the possibility to modulate inflammatory [89] and immune responses [90]. Early studies have shown that the dietary intake of selenium is low in SSc patients, but this is not dependent on a dietary deficiency, but rather malabsorption syndrome [86].

The antioxidant properties of zinc have also been confirmed. Zinc is needed for the proper functioning of MMPsthe enzymes that reveal proteolytic activities and regulate cell-matrix composition in systemic sclerosis [91-93].

3.2.3. Other Nutritional Antioxidants. More recently, natural antioxidants such as polyphenols, which are present in many plant foods, have been studied as possible nutritional factors in decreasing oxidative stress. One of these is (-)-epigallocatechin-3-gallate (EGCG) present in green tea extracts (Camellia sinensis), which is effective in eliminating oxidative stress in SSc. EGCG reveals the ability to scavenge free radicals, inhibits the formation of ROS (such as $\mathrm{O}_{2}{ }^{--}$ and $\mathrm{ONOO}^{-}$), and reduces oxidative stress [94]. EGCG has a higher potential antioxidant capability than $\alpha$-tocopherol or vitamin C [95] and reduces ROS synthesis through decreasing NADPH oxidase expression [96]. In SSc, EGCG inhibits transcription factors (Nrf2, NF- $\kappa \mathrm{B}$, and $\mathrm{AP}-1$ ), regulates multiple signal transduction pathways such as MAP kinases, and induces protective antioxidant enzymes such as HO-1 [15, $21,23]$. In animal models, EGCG reveals anti-inflammatory and antifibrotic properties via regulation of PDGF-induced $\alpha 1$ (I) collagen, fibronectin, and $\alpha$-SMA [26, 27]. In SSc patients and healthy controls, EGCG reduces oxidative stress through inhibition of ROS stimulated by TGF $\beta$ in human dermal fibroblasts [16].

Another plant antioxidant is Ginkgo biloba extract (a Chinese herb), which suppresses inflammatory cytokinestimulated endothelial adhesiveness to human monocytic cells by attenuating intracellular ROS formation [97]. This attenuates the TNF- $\alpha$-induced vascular cell surface and total protein expression of adhesion molecules such as VCAM1 and ICAM-1 (in SSc patients, increased levels of TNF- $\alpha$ in tissue and blood correlate with disease activity) [29, 35]. This beneficial influence of Ginkgo biloba may also reduce oxidative stress processes in systemic sclerosis [98] and seems to be effective in reducing the number of Raynaud's attacks per week in patients suffering from Raynaud's phenomenon [99].

3.2.4. Synthetic Antioxidants. Attempts using synthetic antioxidants (such as probucol-hypolipidemic medication) have also been made and have revealed a reduction in the frequency and severity of Raynaud's attacks [100, 101].
However, in a study by Herrick et al., antioxidative therapy was ineffective in limited cutaneous SSc, which could be explained by the late implementation of antioxidants. The authors suggested that the addition of antioxidants at the onset of the disease (before irreversible tissue injury) may give positive results [17].

In many studies, NAC has shown a beneficial influence on SSc, diminishing cellular ROS in fibroblast and replenishing free cellular thiols $[6,9,18-20]$. NAC inhibits fibroblast proliferation and collagen synthesis [6] and reduces peroxynitrite $\left(\mathrm{ONOO}^{-}\right)$synthesis by activated lung macrophages from SSc patients in vitro [68]. Moreover, it potentiates the antiproliferative effect of 5-fluorouracil (5FU)-one of the immunosuppressants used in lung idiopathic interstitial fibrosis [68]. In consequence, fibroblast proliferation is inhibited by $78 \%$ [9]. NAC also beneficially influences cultured vascular smooth muscle cells, where it reduces PDGFR phosphorylation and increases protein tyrosine phosphatases (PTP) activity [102]. This improves the vascular symptoms of Raynaud's phenomenon in patients with SSc $[14,18,19]$.

\section{Conclusion}

Undeniably, oxidative stress (local and systemic) is one of the important mechanisms which cause intracellular changes and stimulate skin and visceral fibrogenesis. Understanding the molecular mechanism of the oxidative cascade in SSc provides a new insight into this disease. Besides this, assaying serum-induced ROS production allows for an estimation of the clinical activity of SSc, which can be followed by appropriate treatment. Currently, we know that such molecules as probucol, NAC, EGCG, polyfenols, and antioxidative vitamins and minerals may be useful in the supportive therapy of SSc and Raynaud's phenomenon (some results are already very promising).

Although recent findings regarding oxidative stress and supportive antioxidant therapy are very encouraging, further studies are necessary to confirm new mechanisms of oxidative cascades in fibroblasts and define the therapeutic potential of analyzed antioxidants in SSc. This may provide the background for possible antioxidative and pharmacological management, which not only could enable effective treatment but maybe also slow down the progression of the disease. If studies confirm the efficacy of nutritional antioxidants, they could provide the basis for specific nutritional recommendations supportive to pharmacological treatment.

\section{Abbreviations}

ADAM17/NOTCH: Disintegrin and metalloproteinase domain-containing protein 17 involved in the activation of the Notch signaling pathway

ADMA: Asymmetric dimethylarginine 
AOPPs: Advance oxidation protein products

ARE: Antioxidant response element

$\alpha$-SMA: $\quad \alpha$-Smooth muscle actin

BAL: $\quad$ Bronchoalveolar lavage

CCL-2: Chemokine ligand-2

dSSc:

EGCG:

Diffuse cutaneous systemic sclerosis

eNOS: $\quad$ Endothelial nitric oxide synthase

(NOS3)

5FU: 5-Fluorouracil

GSH: Glutathione

GSH-Px: Glutathione peroxidase

$\mathrm{H}_{2} \mathrm{O}_{2}$ : Hydrogen peroxide

HOCl: Hypochlorous acid

HO-1: Haemoxygenase-1

iNOS: Inducible nitric oxide synthase (NOS2)

ISSc: Limited cutaneous systemic sclerosis

MMP: $\quad$ Matrix metalloproteinase-1

NAC: N-Acetyl-1-cysteine

NADPH: Nicotinamide adenine dinucleotide phosphate

NOS: $\quad$ Nitric oxide synthase

nNOS: Neuronal nitric oxide synthase

NO: $\quad$ Nitric oxide

$\mathrm{NO}_{2}{ }^{-}: \quad$ Nitrite

$\mathrm{NO}_{3}{ }^{-}: \quad$ Nitrate

NOS: $\quad$ Nitric oxide synthase (NOS1)

Nrf2: $\quad$ Nuclear factor erythroid-2-related

factor 2

Nox: NADPH oxidase-nicotinamide adenine dinucleotide

phosphate-oxidase

$\mathrm{O}_{2}{ }^{\cdot-}$ : $\quad$ Superoxide anions

$\cdot \mathrm{OH}: \quad$ Hydroxyl radicals

$\mathrm{ONOO}^{-}$: $\quad$ Peroxynitrite

oxLDL: Oxidized low-density lipoprotein

PDGF: $\quad$ Antiplatelet derived growth factor

PDGFR: Platelet derived growth factor receptor

PRP: $\quad$ Protein tyrosine phosphatases

(PHTE)2NQ: 2,3-Bis

(phenyltellanyl)-naphthoquinone

PTP1B: $\quad$ Protein tyrosine phosphatases 1B

PAH: $\quad$ Pulmonary arterial hypertension

Ras proteins: A family of related proteins involved in transmitting signals within cells through the Ras pathway, which belong to a class of proteins called small GTPase

RDAs: $\quad$ Recommended dietary allowances

RhoA: $\quad$ Ras homolog gene family, member A (a small GTPase protein regulating the actin cytoskeleton in the formation of stress fibers)

ROCK: $\quad$ Rho kinase

ROS: $\quad$ Reactive oxygen species

STPR: $\quad$ Skin thickening progression rate

TGF- $\beta$ : $\quad$ Transforming growth factor $\beta$.

\section{Conflict of Interests}

The authors declare that there is no conflict of interests regarding the publication of this paper.

\section{References}

[1] M. C. Tamby, Y. Chanseaud, L. Guillevin, and L. Mouthon, "New insights into the pathogenesis of systemic sclerosis," Autoimmunity Reviews, vol. 2, no. 3, pp. 152-157, 2003.

[2] A. Gabrielli, E. V. Avvedimento, and T. N. Krieg, "Scleroderma," The New England Journal of Medicine, vol. 360, no. 19, pp. 19892003, 2009.

[3] C. P. Denton, C. M. Black, and D. J. Abraham, "Mechanisms and consequences of fibrosis in systemic sclerosis," Nature Clinical Practice Rheumatology, vol. 2, no. 3, pp. 134-144, 2006.

[4] J. Varga and D. Abraham, "Systemic sclerosis: a prototypic multisystem fibrotic disorder," The Journal of Clinical Investigation, vol. 117, no. 3, pp. 557-567, 2007.

[5] A. L. Herrick and J. Worthington, "Genetic epidemiology: systemic sclerosis," Arthritis Research, vol. 4, no. 3, pp. 165-168, 2002.

[6] P. Sambo, S. S. Baroni, M. Luchetti et al., "Oxidative stress in scleroderma: maintenance of scleroderma fibroblast phenotype by the constitutive up-regulation of reactive oxygen species generation through the NADPH oxidase complex pathway," Arthritis and Rheumatism, vol. 44, no. 11, pp. 2653-2664, 2001.

[7] S. Svegliati, R. Cancello, P. Sambo et al., "Platelet-derived growth factor and reactive oxygen species (ROS) regulate Ras protein levels in primary human fibroblasts via ERK1/2: amplification of ROS and Ras in systemic sclerosis fibroblasts," Journal of Biological Chemistry, vol. 280, no. 43, pp. 36474-36482, 2005.

[8] F. Ogawa, K. Shimizu, E. Muroi et al., "Serum levels of 8isoprostane, a marker of oxidative stress, are elevated in patients with systemic sclerosis," Rheumatology, vol. 45, no. 7, pp. 815818, 2006.

[9] A. Servettaz, P. Guilpain, C. Goulvestre et al., "Radical oxygen species production induced by advanced oxidation protein products predicts clinical evolution and response to treatment in systemic sclerosis," Annals of the Rheumatic Diseases, vol. 66, no. 9, pp. 1202-1209, 2007.

[10] A. L. Herrick and M. Matucci Cerinic, "The emerging problem of oxidative stress and the role of antioxidants in systemic sclerosis," Clinical and Experimental Rheumatology, vol. 19, no. 1, pp. 4-8, 2001.

[11] G. Simonini, A. Pignone, S. Generini, F. Falcini, and M. M. Cerinic, "Emerging potentials for an antioxidant therapy as a new approach to the treatment of systemic sclerosis," Toxicology, vol. 155 , no. $1-3$, pp. 1-15, 2000.

[12] A. C. Howard, A. K. McNeil, and P. L. McNeil, "Promotion of plasma membrane repair by vitamin E," Nature Communications, vol. 2, no. 1, article 597, 2011.

[13] P. Ostojic and N. Damjanov, "Effects of micronutrient antioxidants (alpha-tocopherol and ascorbic acid) on skin thickening and lung function in patients with early diffuse systemic sclerosis," Rheumatology International, vol. 31, no. 8, pp. 10511054, 2011.

[14] F. Salsano, C. Letizia, M. Proietti et al., "Significant changes of peripheral perfusion and plasma adrenomedullin levels in $\mathrm{N}$-acetylcysteine long term treatment of patients with sclerodermic Raynauds phenomenon," International Journal of 
Immunopathology and Pharmacology, vol. 18, no. 4, pp. 761-770, 2005.

[15] H.-K. Na and Y.-J. Surh, "Intracellular signaling network as a prime chemopreventive target of (-)-epigallocatechin gallate," Molecular Nutrition and Food Research, vol. 50, no. 2, pp. 152159, 2006.

[16] A. Dooley, X. Shi-Wen, N. Aden et al., "Modulation of collagen type I, fibronectin and dermal fibroblast function and activity, in systemic sclerosis by the antioxidant epigallocatechin-3gallate," Rheumatology, vol. 49, no. 11, pp. 2024-2036, 2010.

[17] A. L. Herrick, S. Hollis, D. Schofield et al., "A double-blind placebo-controlled trial of antioxidant therapy in limited cutaneous systemic sclerosis," Clinical and Experimental Rheumatology, vol. 18, no. 3, pp. 349-356, 2000.

[18] P. Sambo, D. Amico, R. Giacomelli et al., "Intravenous Nacetylcysteine for treatment of Raynaud's phenomenon secondary to systemic sclerosis: a pilot study," The Journal of Rheumatology, vol. 28, no. 10, pp. 2257-2262, 2001.

[19] E. Rosato, F. Borghese, S. Pisarri, and F. Salsano, “The treatment with $\mathrm{N}$-acetylcysteine of Raynaud's phenomenon and ischemic ulcers therapy in sclerodermic patients: a prospective observational study of 50 patients," Clinical Rheumatology, vol. 28, no. 12, pp. 1379-1384, 2009.

[20] P.-S. Tsou, N. N. Talia, A. J. Pinney et al., "Effect of oxidative stress on protein tyrosine phosphatase $1 \mathrm{~B}$ in scleroderma dermal fibroblasts," Arthritis \& Rheumatism, vol. 64, no. 6, pp. 1978-1989, 2012.

[21] J. R. Tsai, H. M. Wang, P. L. Liu et al., "High expression of heme oxygenase-1 is associated with tumor invasiveness and poor clinical outcome in non-small cell lung cancer patients," Cellular Oncology, vol. 35, no. 6, pp. 461-471, 2012.

[22] C. M. Shih, Y. H. Chen, Y. W. Lin et al., "MK-0626, a dipeptidyl peptidase- 4 inhibitor, improves neovascularization by increasing both the number of circulating endothelial progenitor cells and endothelial nitric oxide synthetase expression," Current Medicinal Chemistry, vol. 21, no. 17, pp. 2012-2022, 2014.

[23] J.-R. Tsai, H.-M. Wang, P.-L. Liu et al., "High expression of heme oxygenase-1 is associated with tumor invasiveness and poor clinical outcome in non-small cell lung cancer patients," Cellular Oncology, vol. 35, no. 6, pp. 461-471, 2012.

[24] A. Servettaz, C. Goulvestre, N. Kavian et al., "Selective oxidation of DNA topoisomerase 1 induces systemic sclerosis in the mouse," Journal of Immunology, vol. 182, no. 9, pp. 5855-5864, 2009.

[25] W. K. Marut, N. Kavian, A. Servettaz et al., "The organotelluride catalyst (PHTE) $)_{2}$ NQ prevents HOCl-induced systemic sclerosis in mouse," The Journal of Investigative Dermatology, vol. 132, no. 4, pp. 1125-1132, 2012.

[26] N. Sriram, S. Kalayarasan, and G. Sudhandiran, "Epigallocatechin-3-gallate exhibits anti-fibrotic effect by attenuating bleomycin-induced glycoconjugates, lysosomal hydrolases and ultrastructural changes in rat model pulmonary fibrosis," Chemico-Biological Interactions, vol. 180, no. 2, pp. 271-280, 2009.

[27] Y. Yasuda, M. Shimizu, H. Sakai et al., “(-)-Epigallocatechin gallate prevents carbon tetrachloride-induced rat hepatic fibrosis by inhibiting the expression of the PDGFR $\beta$ and IGF-1R," Chemico-Biological Interactions, vol. 182, no. 2-3, pp. 159-164, 2009.

[28] H. Hardardóttir, H. A. C. van Helvoort, M. C. Vonk, F. H. J. van den Hoogen, P. N. R. Dekhuijzen, and Y. F. Heijdra, "Exercise in systemic sclerosis intensifies systemic inflammation and oxidative stress," Scandinavian Journal of Rheumatology, vol. 39, no. 1, pp. 63-70, 2010.

[29] H. Ihn, S. Sato, M. Fujimoto et al., "Characterization of autoantibodies to endothelial cells in systemic sclerosis (SSc): association with pulmonary fibrosis," Clinical and Experimental Immunology, vol. 119, no. 1, pp. 203-209, 2000.

[30] P. García de La Peña-Lefebvre, Y. Chanseaud, M. C. Tamby et al., "IgG reactivity with a $100-\mathrm{kDa}$ tissue and endothelial cell antigen identified as topoisomerase 1 distinguishes between limited and diffuse systemic sclerosis patients," Clinical Immunology, vol. 111, no. 3, pp. 241-251, 2004.

[31] S. S. Baroni, M. Santillo, F. Bevilacqua et al., "Stimulatory autoantibodies to the PDGF receptor in systemic sclerosis," The New England Journal of Medicine, vol. 354, no. 25, pp. 26672676, 2006.

[32] N. Kavian, A. Servettaz, C. Mongaret et al., “Targeting ADAM17/notch signaling abrogates the development of systemic sclerosis in a murine model," Arthritis and Rheumatism, vol. 62, no. 11, pp. 3477-3487, 2010.

[33] A. Laurent, C. Nicco, C. Chéreau et al., "Controlling tumor growth by modulating endogenous production of reactive oxygen species," Cancer Research, vol. 65, no. 3, pp. 948-956, 2005.

[34] C. Nicco, A. Laurent, C. Chereau, B. Weill, and F. Batteux, "Differential modulation of normal and tumor cell proliferation by reactive oxygen species," Biomedicine and Pharmacotherapy, vol. 59, no. 4, pp. 169-174, 2005.

[35] M. J. Morgan and Z.-G. Liu, "Reactive oxygen species in TNF $\alpha$ induced signaling and cell death," Molecules and Cells, vol. 30, no. 1, pp. 1-12, 2010.

[36] R. Coriat, W. Marut, M. Leconte et al., "The organotelluride catalyst LAB027 prevents colon cancer growth in the mice," Cell Death and Disease, vol. 2, no. 8, article e191, 2011.

[37] P. Lonkar and P. C. Dedon, "Reactive species and DNA damage in chronic inflammation: reconciling chemical mechanisms and biological fates," International Journal of Cancer, vol. 128, no. 9, pp. 1999-2009, 2011.

[38] K. Takagi, Y. Kawaguchi, M. Hara, T. Sugiura, M. Harigai, and N. Kamatani, "Serum nitric oxide (NO) levels in systemic sclerosis patients: Correlation between NO levels and clinical features," Clinical and Experimental Immunology, vol. 134, no. 3, pp. 538544, 2003.

[39] G. N. Andersen, K. Caidahl, E. Kazzam et al., "Correlation between increased nitric oxide production and markers of endothelial activation in systemic sclerosis: findings with the soluble adhesion molecules e-selectin, intercellular adhesion molecule 1, and vascular cell adhesion molecule 1," Arthritis and Rheumatism, vol. 43, no. 5, pp. 1085-1093, 2000.

[40] K. Shimizu, F. Ogawa, E. Muroi et al., "Increased serum levels of nitrotyrosine, a marker for peroxynitrite production, in systemic sclerosis," Clinical and Experimental Rheumatology, vol. 25, no. 2, pp. 281-286, 2007.

[41] S. Y. Low, M. Sabetkar, K. R. Bruckdorfer, and K. M. Naseem, "The role of protein nitration in the inhibition of platelet activation by peroxynitrite," FEBS Letters, vol. 511, no. 1-3, pp. 59-64, 2002.

[42] C. Bogdan, "Nitric oxide and the regulation of gene expression," Trends in Cell Biology, vol. 11, no. 2, pp. 66-75, 2001.

[43] A. Dooley, K. R. Bruckdorfer, and D. J. Abraham, "Modulation of fibrosis in systemic sclerosis by nitric oxide and antioxidants," 
Cardiology Research and Practice, vol. 2012, Article ID 521958, 9 pages, 2012.

[44] A. Sud, M. Khullar, A. Wanchu, and P. Bambery, "Increased nitric oxide production in patients with systemic sclerosis," Nitric Oxide-Biology and Chemistry, vol. 4, no. 6, pp. 615-619, 2000.

[45] R. Bruckdorfer, "The basics about nitric oxide," Molecular Aspects of Medicine, vol. 26, no. 1-2, pp. 3-31, 2005.

[46] M. M. Cerinic and M. B. Kahaleh, "Beauty and the beast. The nitric oxide paradox in systemic sclerosis," Rheumatology, vol. 41, no. 8, pp. 843-847, 2002.

[47] M. P. Chung, M. M. Monick, N. Y. Hamzeh, N. S. Butler, L. S. Powers, and G. W. Hunninghake, "Role of repeated lung injury and genetic background in bleomycin-induced fibrosis," The American Journal of Respiratory Cell and Molecular Biology, vol. 29, no. 3, part 1, pp. 375-380, 2003.

[48] C. Lunardi, M. Dolcino, D. Peterlana et al., "Antibodies against human cytomegalovirus in the pathogenesis of systemic sclerosis: a gene array approach," PLoS Medicine, vol. 3, no. 1, article e2, 2006.

[49] B. Fubini and A. Hubbard, "Reactive oxygen species (ROS) and reactive nitrogen species (RNS) generation by silica in inflammation and fibrosis," Free Radical Biology and Medicine, vol. 34, no. 12, pp. 1507-1516, 2003.

[50] V. Witko-Sarsat, M. Friedlander, C. Capeillère-Blandin et al., "Advanced oxidation protein products as a novel marker of oxidative stress in uremia," Kidney International, vol. 49, no. 5, pp. 1304-1313, 1996.

[51] R. Solans, C. Motta, R. Sola et al., "Abnormalities of erythrocyte membrane fluidity, lipid composition, and lipid peroxidation in systemic sclerosis," Arthritis \& Rheumatism, vol. 43, no. 4, pp. 894-900, 2000.

[52] C. M. Stein, S. B. Tanner, J. A. Awad, L. J. Roberts II, and J. D. Morrow, "Evidence of free radical-mediated injury (isoprostane overproduction) in scleroderma," Arthritis and Rheumatism, vol. 39, no. 7, pp. 1146-1150, 1996.

[53] P. Montuschi, G. Ciabattoni, P. Pared et al., "8-Isoprostane as a biomarker of oxidative stress in interstitial lung diseases," American Journal of Respiratory and Critical Care Medicine, vol. 158, no. 5, part 1, pp. 1524-1527, 1998.

[54] R. R. Freedman, R. Girgis, and M. D. Mayes, "Endothelial and adrenergic dysfunction in Raynaud's phenomenon and scleroderma," Journal of Rheumatology, vol. 26, no. 11, pp. 23862388, 1999.

[55] A. L. Herrick, "Pathogenesis of Raynaud's phenomenon," Rheumatology, vol. 44, no. 5, pp. 587-596, 2005.

[56] L. Iuliano, D. Praticò, C. Greco et al., "Angioplasty increases coronary sinus F2-isoprostane formation: evidence in vivo oxidative stress during PTCA," Journal of the American College of Cardiology, vol. 37, no. 1, pp. 76-80, 2001.

[57] J. M. Johnson, T. C. Yen, K. Zhao, and W. A. Kosiba, "Sympathetic, sensory, and nonneuronal contributions to the cutaneous vasoconstrictor response to local cooling," American Journal of Physiology: Heart and Circulatory Physiology, vol. 288, no. 4, pp. H1573-H1579, 2005.

[58] F. Yamazaki, R. Sone, K. Zhao, G. E. Alvarez, W. A. Kosiba, and J. M. Johnson, "Rate dependency and role of nitric oxide in the vascular response to direct cooling in human skin," Journal of Applied Physiology, vol. 100, no. 1, pp. 42-50, 2006.

[59] T. Tingey, J. Shu, J. Smuczek, and J. Pope, "Meta-analysis of healing and prevention of digital ulcers in systemic sclerosis," Arthritis Care and Research, vol. 65, no. 9, pp. 1460-1471, 2013.
[60] N. A. Flavahan, "Regulation of vascular reactivity in scleroderma: new insights into Raynaud's phenomenon," Rheumatic Disease Clinics of North America, vol. 34, no. 1, pp. 81-87, 2008.

[61] M. Philipp, M. Brede, and L. Hein, "Physiological significance of $\alpha 2$-adrenergic receptor subtype diversity: one receptor is not enough," The American Journal of Physiology-Regulatory Integrative and Comparative Physiology, vol. 283, no. 2, pp. R287-R295, 2002.

[62] J. P. Cooke and J. M. Marshall, "Mechanisms of Raynaud's disease," Vascular Medicine, vol. 10, no. 4, pp. 293-307, 2005.

[63] H.-Y. Cho, S. P. Reddy, A. DeBiase, M. Yamamoto, and S. R. Kleeberger, "Gene expression profiling of NRF2-mediated protection against oxidative injury," Free Radical Biology and Medicine, vol. 38, no. 3, pp. 325-343, 2005.

[64] H.-Y. Cho, S. P. M. Reddy, M. Yamamoto, and S. R. Kleeberger, "The transcription factor NRF2 protects against pulmonary fibrosis," The FASEB Journal, vol. 18, no. 11, pp. 1258-1260, 2004.

[65] C. A. Piantadosi, C. M. Withers, R. R. Bartz et al., "Heme oxygenase-1 couples activation of mitochondrial biogenesis to anti-inflammatory cytokine expression," Journal of Biological Chemistry, vol. 286, no. 18, pp. 16374-16385, 2011.

[66] F. Jiang, S. J. Roberts, S. R. Datla, and G. J. Dusting, "NO modulates NADPH oxidase function via heme oxygenase-1 in human endothelial cells," Hypertension, vol. 48, no. 5, pp. 950957, 2006.

[67] R. H. Böger, P. Vallance, and J. P. Cooke, "Asymmetric dimethylarginine (ADMA): a key regulator of nitric oxide synthase," Atherosclerosis Supplements, vol. 4, no. 4, pp. 1-3, 2003.

[68] R. Ammendola, M. R. Ruocchio, G. Chirico et al., "Inhibition of $\mathrm{NADH}$ /NADPH oxidase affects signal transduction by growth factor receptors in normal fibroblasts," Archives of Biochemistry and Biophysics, vol. 397, no. 2, pp. 253-257, 2002.

[69] H.-L. Fung, S. Chong, E. Kowaluk, K. Hough, and M. Kakemi, "Mechanisms for the pharmacologic interaction of organic nitrates with thiols. Existence of an extracellular pathway for the reversal of nitrate vascular tolerance by N-acetylcysteine," Journal of Pharmacology and Experimental Therapeutics, vol. 245, no. 2, pp. 524-530, 1988.

[70] P. Failli, L. Palmieri, C. D’Alfonso et al., "Effect of N-acetyl-Lcysteine on peroxynitrite and superoxide anion production of lung alveolar macrophages in systemic sclerosis," Nitric Oxide: Biology and Chemistry, vol. 7, no. 4, pp. 277-282, 2002.

[71] M. Demedts, J. Behr, R. Buhl et al., "High-dose acetylcysteine in idiopathic pulmonary fibrosis," The New England Journal of Medicine, vol. 353, no. 21, pp. 2229-2242, 2005.

[72] R. Samarakoon, J. M. Overstreet, and P. J. Higgins, “TGF-beta signaling in tissue fibrosis: redox controls, target genes and therapeutic opportunities," Cellular Signalling, vol. 25, no. 1, pp. 264-268, 2013.

[73] I.-T. Lee and C.-M. Yang, "Role of NADPH oxidase/ROS in pro-inflammatory mediators-induced airway and pulmonary diseases," Biochemical Pharmacology, vol. 84, no. 5, pp. 581-590, 2012.

[74] M. Jinnin, H. Ihn, K. Yamane, and K. Tamaki, "Interleukin-13 stimulates the transcription of the human $\alpha 2$ (I) collagen gene in human dermal fibroblasts," The Journal of Biological Chemistry, vol. 279, no. 40, pp. 41783-41791, 2004.

[75] B. Maurer, J. Stanczyk, A. Jüngel et al., "MicroRNA-29, a key regulator of collagen expression in systemic sclerosis," Arthritis and Rheumatism, vol. 62, no. 6, pp. 1733-1743, 2010. 
[76] T. Yamamoto, "The bleomycin-induced scleroderma model: what have we learned for scleroderma pathogenesis?" Archives of Dermatological Research, vol. 297, no. 8, pp. 333-344, 2006.

[77] A.-C. Lundberg, A. Akesson, and B. Akesson, "Dietary intake and nutritional status in patients with systemic sclerosis," Annals of the Rheumatic Diseases, vol. 51, no. 10, pp. 1143-1148, 1992.

[78] P. Di Mascio, M. E. Murphy, and H. Sies, "Antioxidant defense systems: the role of carotenoids, tocopherols, and thiols," The American Journal of Clinical Nutrition, vol. 53, no. 1, supplement, pp. 194S-200S, 1991.

[79] K. Tran, J. T. Wong, E. Lee, A. C. Chan, and P. C. Choy, "Vitamin E potentiates arachidonate release and phospholipase A2 activity in rat heart myoblastic cells," Biochemical Journal, vol. 319, no. 2, pp. 385-391, 1996.

[80] N. Kono, U. Ohto, T. Hiramatsu et al., "Impaired $\alpha$-TTP-PIPs interaction underlies familial vitamin E deficiency," Science, vol. 340, no. 6136, pp. 1106-1110, 2013.

[81] Office of Dietary Supplements, "National Institutes of Health Dietary Supplement Fact Sheet: Vitamin E," http://www.ods.od.nih.gov/factsheets/vitamine.asp.

[82] J.-L. Cracowski, S. Girolet, B. Imbert et al., "Effects of shortterm treatment with vitamin $\mathrm{E}$ in systemic sclerosis: a double blind, randomized, controlled clinical trial of efficacy based on urinary isoprostane measurement," Free Radical Biology and Medicine, vol. 38, no. 1, pp. 98-103, 2005.

[83] M. E. Mavrikakis, J. P. Lekakis, C. M. Papamichael, K. S. Stamatelopoulos, C. C. Kostopoulos, and S. F. Stamatelopoulos, "Ascorbic acid does not improve endothelium-dependent flowmediated dilatation of the brachial artery in patients with Raynaud's phenomenon secondary to systemic sclerosis," International Journal for Vitamin and Nutrition Research, vol. 73, no. 1, pp. 3-7, 2003.

[84] E. Herrera and C. Barbas, "Vitamin E: action, metabolism and perspectives," Journal of Physiology and Biochemistry, vol. 57, no. 2, pp. 43-56, 2001.

[85] G. L. Tipoe, T.-M. Leung, M.-W. Hung, and M.-L. Fung, “Green tea polyphenols as an anti-oxidant and anti-inflammatory agent for cardiovascular protection," Cardiovascular and Hematological Disorders-Drug Targets, vol. 7, no. 2, pp. 135-144, 2007.

[86] A. L. Herrick, H. Worthington, F. Rieley et al., "Dietary intake of micronutrient antioxidants in relation to blood levels in patients with systemic sclerosis," The Journal of Rheumatology, vol. 23, no. 4, pp. 650-653, 1996.

[87] L.-S. Teh, C. W. Johns, J. L. Shaffer et al., "Ascorbic acid absorption in patients with systemic sclerosis," The Journal of Rheumatology, vol. 24, no. 12, pp. 2353-2357, 1997.

[88] P. Suwannalert, P. Boonsiri, T. Khampitak, K. Khampitak, P. Sriboonlue, and P. Yongvanit, "The levels of lycopene, $\alpha$ tocopherol and a marker of oxidative stress in healthy northeast Thai elderly," Asia Pacific Journal of Clinical Nutrition, vol. 16, supplement 1, pp. 27-30, 2007.

[89] J. L. Toivanen, "Effects of selenium, vitamin E and vitamin C on human prostacyclin and thromboxane synthesis in vitro," Prostaglandins Leukotrienes and Medicine, vol. 26, no. 3, pp. 265-280, 1987.

[90] L. Kiremidjian-Schumacher and G. Stotzky, "Selenium and immune responses," Environmental Research, vol. 42, no. 2, pp. 277-303, 1987.

[91] M. Ram, Y. Sherer, and Y. Shoenfeld, "Matrix metalloproteinase9 and autoimmune diseases," Journal of Clinical Immunology, vol. 26, no. 4, pp. 299-307, 2006.
[92] Q. Chen, M. Jin, F. Yang, J. Zhu, Q. Xiao, and L. Zhang, "Matrix metalloproteinases: inflammatory regulators of cell behaviors in vascular formation and remodeling," Mediators of Inflammation, vol. 2013, Article ID 928315, 14 pages, 2013.

[93] G. J. Elias, M. Ioannis, P. Theodora et al., "Circulating tissue inhibitor of matrix metalloproteinase-4 (TIMP-4) in systemic sclerosis patients with elevated pulmonary arterial pressure," Mediators of Inflammation, vol. 2008, Article ID 164134, 8 pages, 2008.

[94] C. Rice-Evans, "Implications of the mechanisms of action of tea polyphenols as antioxidants in vitro for chemoprevention in humans," Proceedings of the Society for Experimental Biology and Medicine, vol. 220, no. 4, pp. 262-266, 1999.

[95] H. Nishikawa, K. Wakano, and S. Kitani, "Inhibition of NADPH oxidase subunits translocation by tea catechin EGCG in mast cell," Biochemical and Biophysical Research Communications, vol. 362, no. 2, pp. 504-509, 2007.

[96] C. P. Denton, T. D. Bunce, M. B. Dorado et al., "Probucol improves symptoms and reduces lipoprotein oxidation susceptibility in patients with Raynaud's phenomenon," Rheumatology, vol. 38, no. 4, pp. 309-315, 1999.

[97] Y.-H. Chen, S.-J. Lin, Y.-L. Chen, P.-L. Liu, and J.-W. Chen, "Anti-inflammatory effects of different drugs/agents with antioxidant property on endothelial expression of adhesion molecules," Cardiovascular \& Hematological Disorders: Drug Targets, vol. 6, no. 4, pp. 279-304, 2006.

[98] J.-W. Chen, Y.-H. Chen, F.-Y. Lin, Y.-L. Chen, and S.-J. Lin, "Ginkgo biloba extract inhibits tumor necrosis factor$\alpha$-induced reactive oxygen species generation, transcription factor activation, and cell adhesion molecule expression in human aortic endothelial cells," Arteriosclerosis, Thrombosis, and Vascular Biology, vol. 23, no. 9, pp. 1559-1566, 2003.

[99] A. H. Muir, R. Robb, M. McLaren, F. Daly, and J. J. F. Belch, "The use of Ginkgo biloba in Raynaud's disease: a double-blind placebo-controlled trial," Vascular Medicine, vol. 7, no. 4, pp. 265-267, 2002.

[100] V. Steen and T. Medsger, "Severe organ involvement in patients with diffuse scleroderma," Arthritis and Rheumatism, vol. 43, no. 11, pp. 2437-2444, 2000.

[101] C. L. Gries and M. L. Scott, "Pathology of selenium deficiency in the chick," Journal of Nutrition, vol. 102, no. 10, pp. 1287-1296, 1972.

[102] K. Kappert, J. Sparwel, Å. Sandin et al., "Antioxidants relieve phosphatase inhibition and reduce PDGF signaling in cultured VSMCs and in restenosis," Arteriosclerosis, Thrombosis, and Vascular Biology, vol. 26, no. 12, pp. 2644-2651, 2006. 


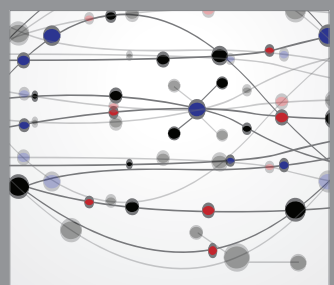

The Scientific World Journal
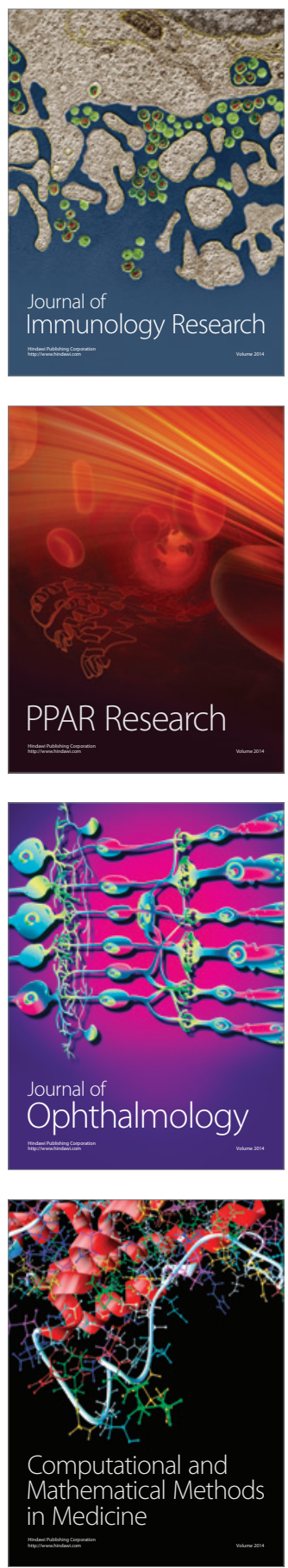

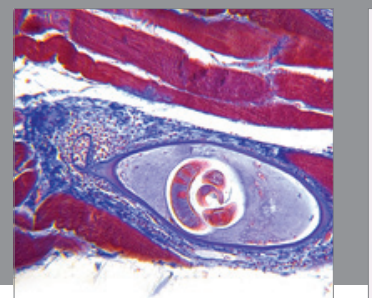

Gastroenterology

Research and Practice
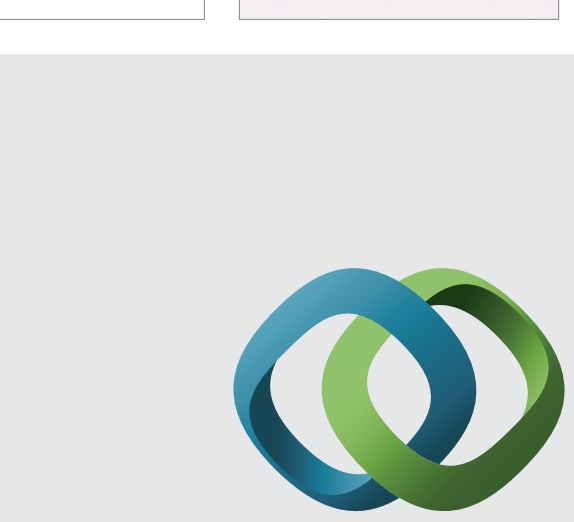

\section{Hindawi}

Submit your manuscripts at

http://www.hindawi.com
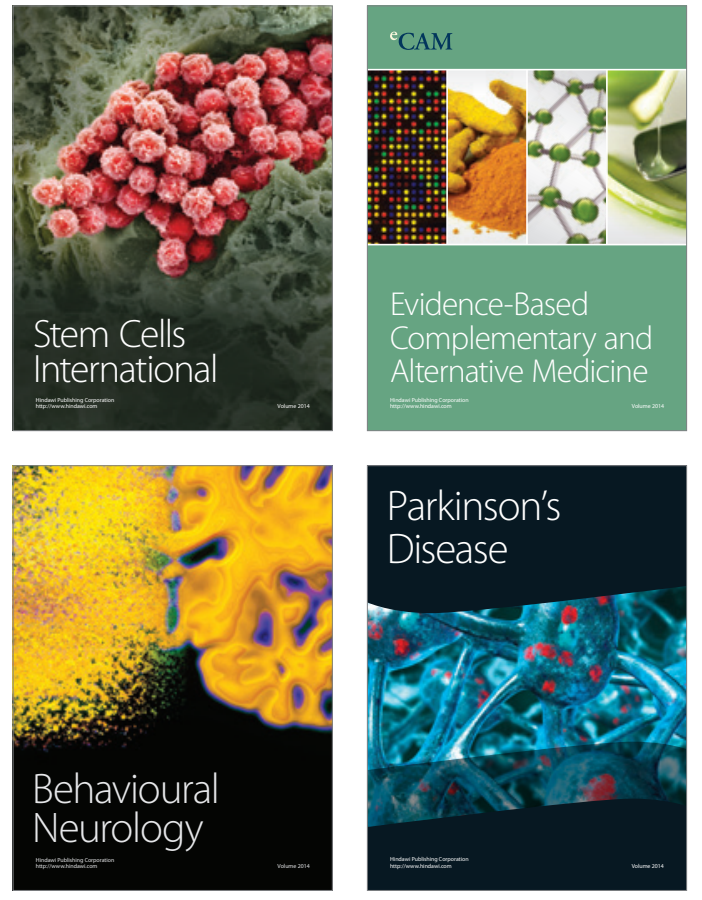
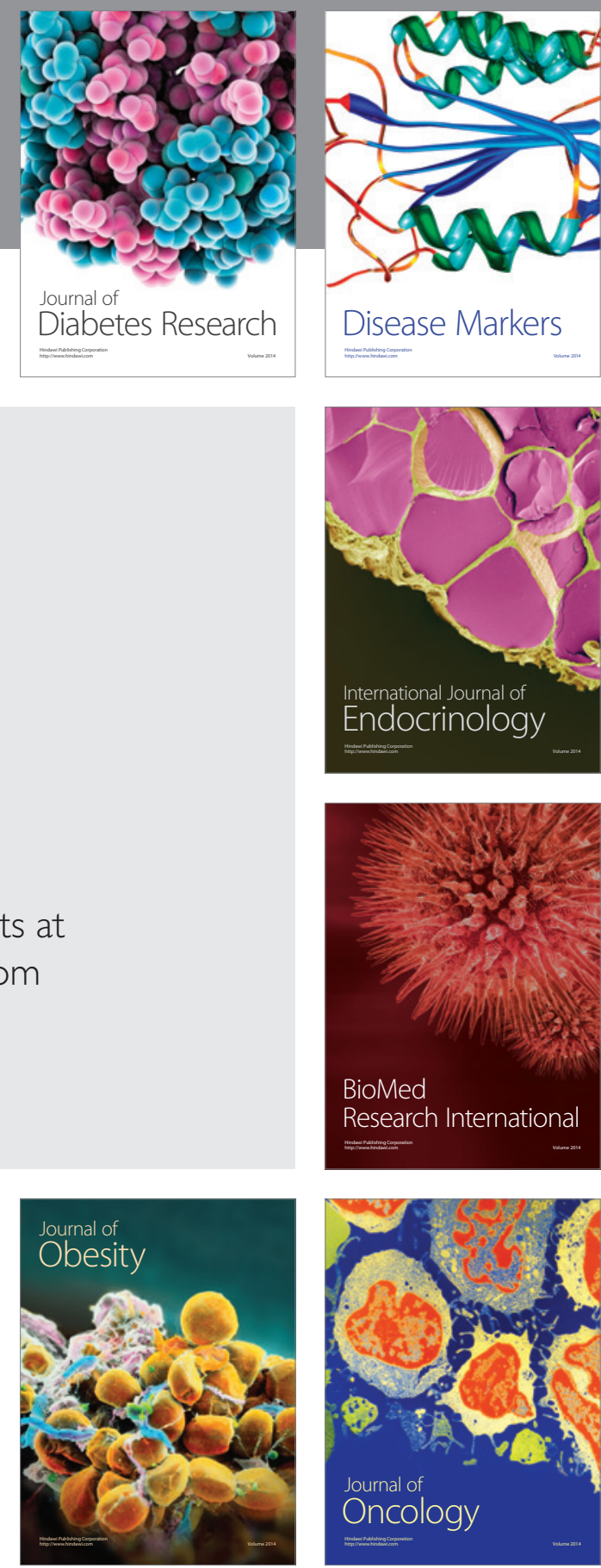

Disease Markers
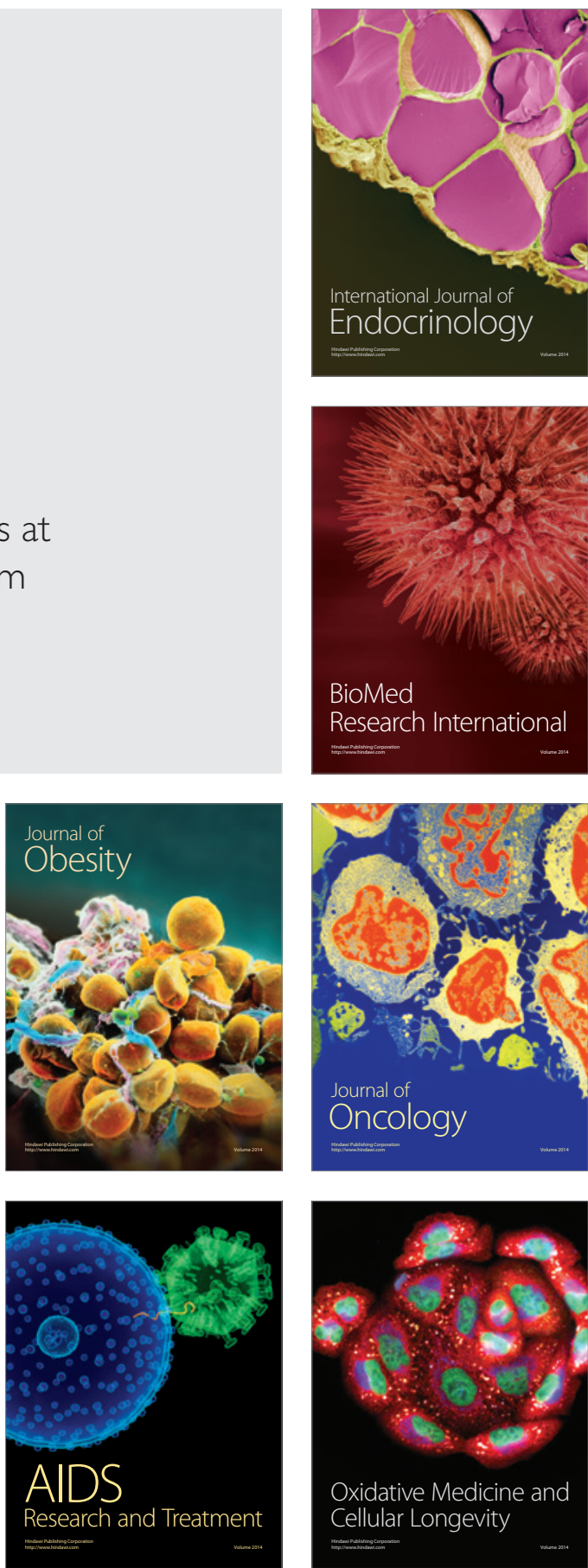